\title{
Pre-seismic, co-seismic and post-seismic displacements associated with the Bhuj 2001 earthquake derived from recent and historic geodetic data
}

\author{
Sridevi Jade ${ }^{1}$, M Mukul ${ }^{1}$, I A Parvez ${ }^{1}$, M B Ananda ${ }^{1}$, P D Kumar ${ }^{1}$, V K Gaur ${ }^{1}$,

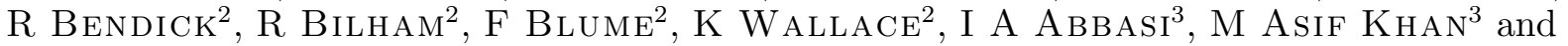 \\ S Ulhadi ${ }^{3}$ \\ ${ }^{1}$ CSIR Centre for Mathematical Modelling and Computer Simulation, Bangalore 560 03\%, India \\ ${ }^{2}$ CIRES 83 Department of Geol. Sci., Univ. of Colorado, Boulder, CO 80309-0399, USA \\ ${ }^{3}$ University of Peshawar, Peshawar 25 120, Pakistan
}

The 26th January 2001 Bhuj earthquake occurred in the Kachchh Rift Basin which has a long history of major earthquakes. Great Triangulation Survey points (GTS) were first installed in the area in 1856-60 and some of these were measured using Global Positioning System (GPS) in the months of February and July 2001. Despite uncertainties associated with repairs and possible reconstruction of points in the past century, the re-measurements reveal pre-seismic, co-seismic and post-seismic deformation related to Bhuj earthquake. More than $25 \mu$-strain contraction north of the epicenter appears to have occurred in the past 140 years corresponding to a linear convergence rate of approximately $10 \mathrm{~mm} / \mathrm{yr}$ across the Rann of Kachchh. Motion of a single point at Jamnagar $150 \mathrm{~km}$ south of the epicenter in the 4 years prior to the earthquake, and GTS-GPS displacements in Kathiawar suggests that pre-seismic strain south of the epicenter was small and differs insignificantly from that measured elsewhere in India. Of the 20 points measured within $150 \mathrm{~km}$ of the epicenter, 12 were made at existing GTS points which revealed epicentral displacements of up to $1 \mathrm{~m}$, and strain changes exceeding $30 \mu$-strain. Observed displacements are consistent with reverse co-seismic slip. Re-measurements in July 2001 of one GTS point (Hathria) and eight new points established in February reveal post-seismic deformation consistent with continued slip on the Bhuj rupture zone.

\section{Introduction}

The Bhuj earthquake occurred on the southern margin of the Kachchh Rift Basin (Bendick et al 2001). Rifting in the Kachchh rift was initiated around $150 \mathrm{Ma}$ and continued to 128-130 Ma. Despite early extensional deformation and the accumulation of considerable thickness of sediments, structures developed within and near the Kachchh Rift Basin (KRB) in the past 10 million years indicate that compressional tectonics in a NE-SW direction has prevailed. The northdipping Kathiawar fault and the south-dipping Nagar Parkar Fault systems that form the south- ern and northern boundaries of the Kachchh Rift Basin respectively, are now active in a reverse sense, consistent with NE-SW compression (Gowd et al 1996). The northern Allah Bund system of thrust faults are north-dipping with transport direction from north to south whereas the southern Kachchh Mainland Fault system of thrust faults dip to the south and indicate south to north transport direction. The zone of transition between the two systems of thrust faults lies almost entirely in the Great Rann. The entire Kachchh Rift Basin has been seismically active; the 1819 earthquake occurred in the northern system of faults whereas the 1956 Anjar and the 2001 Bhuj earthquake

Keywords. Global Positioning System (GPS) Geodesy; Great Triangulation Survey (GTS); displacements; Bhuj earthquake; strain; baseline lengths. 
occurred in the southern system of thrust faults (Jade et al 2002). Felt earthquakes are recorded throughout the 19th century although their locations are not well known. The Bhuj 2001 earthquake was initially thought to have originated on the Kachchh Mainland Fault; subsequent analysis of aftershocks and geology have indicated that the hypo-centre of the 2001 earthquake was located north of the Kachchh Mainland Fault on a blind thrust dipping $40^{\circ}-50^{\circ} \mathrm{S}$ with ENE-WSW strike. Its great depth and absence of surface faulting renders its relationship to mapped surface faulting enigmatic.

\section{The 26th January 2001 earthquake}

Several teleseismic interpretations of the rupture parameters of the Bhuj earthquake have been proposed (USGS, Harvard CMT, Anatoli 2001; Sato et al 2001). These embrace a range of rupture areas, epicentral locations and slip vectors. A common feature of these solutions when constrained by post seismic aftershock data is that reverse slip occurred on a buried, steeply-dipping, $40 \times 40 \mathrm{~km}^{2}$ fault plane, and that the dip of this fault was to the SSW. Rupture appears to have been confined to depths below $9 \mathrm{~km}$ depth and to have extended to at least $40 \mathrm{~km}$. Maximum slip in these models varies from 3 to $16 \mathrm{~m}$. This combined with its relatively small rupture area implies high stress drop (10-25 MPa).

Micro-earthquake networks operated in the epicentral region reveal a dense cloud of aftershocks $70^{\circ}-70.5^{\circ} \mathrm{E}, 23.3^{\circ}-23.7^{\circ} \mathrm{N}$, and between depths of 9 to $35 \mathrm{~km}$. Although a single fault plane can be weakly distinguished in part of these data (Negeshi et al 2002; Bodin et al 2001) dipping at $50^{\circ} \mathrm{SSE}$, many more aftershocks occur off this rupture plane than on it.

The teleseismic data require that slip tapers rapidly from the centroid of the main shock (Anatoli 2001; Negeshi et al 2002). Assuming a 40-kmwide equi-dimensional rupture plane and $15 \mathrm{~m}$ of maximum slip, symmetrically partitioned between the hanging wall and foot wall, we calculate that linear strains along the fault plane exceeded $187 \times$ $10^{-6}$ (187 $\mu$-strain). Because the slip distribution is non-linear, much higher fault strains would have occurred locally, consistent with the large and varied nature of aftershocks in the volume adjoining the main rupture.

\section{Geodetic observations of co-seismic slip}

Geodetic measurements in the epicentral region offer an alternative method to estimate the geo- metry of rupture. An extensive and unusually dense network of accurately measured survey control points exists above part of the rupture area as a result of its location near the junction of three geodetic series installed by the Great Trigonometrical Survey of India (GTS) in the period 18551865 (Cole 1890; Strahan 1893; Thuillier 1894; figure 1). Two of these networks follow the mainland of Kachchh westward (the Cutch Coast Series and the Cutch Mainland Series) and the third passes north-south from the Calcutta Longitudinal Series into the Kathiawar Peninsula (The Kattywar Meridional Series). Although many of these points were installed in 1859-60, a subset of these were re-measured in 1959 but these data have not been made publicly available.

The area northwest of the rupture zone is almost completely devoid of control points for almost $100 \mathrm{~km}$ due to the presence of the Great Rann of Kachchh, a salt flat interrupted by occasional "islands" of rock, spaced too far apart for accurate triangulation. One solitary trigonometrical point was installed in the Rann of Kachchh to provide figural strength to the 1859 triangulation.

Most of the GTS points in Kachchh occupy commanding hill-top points locations, or are placed on structures that provide a distant view to an adjoining point. These early marks are often inconvenient for GPS measurements either due to difficulty of access or due to difficulties in sub-cm centering accuracy. Typical construction started with a ground level or shallow buried lower stone tablet inscribed with a dot and circle, surmounted by a masonry column 1-4m high and finished with a flat masonry lid capped by a second inscribed stone concentric with the first. A hollow central masonry chimney permitted alignment of the two stones for verification purposes. Four of the epicentral GTS points were damaged or destroyed by the earthquake. Tower sites at Wandia-II and Bachau-I were lost completely due to the collapse of the structures supporting both their upper and lower tablets. The core pillar at Narra-XIV was destroyed during coseismic battering by its surrounding rubble observing platform. The remnants of the trigonometrical point were found in a low pile spread over a $10 \mathrm{~m}$ region. In a few cases the upper marks were shifted by the shaking but the co-located lower marks were undisturbed (Gangta-VII and Kanduka-IX). Maintenance of the masonary control points in the past century is in evidence. In one case a destroyed 1859 trigonometrical point (Dajka-VI) had been reconstructed (presumably in 1949) $1.6 \mathrm{~km}$ west of the original point. A single solid-rock engraved GTS point was recovered - on the granite summit of the Nagar Parkar in Pakistan.

We report here GPS data obtained in February from one GTS point and 8 new GPS points (table 1, 


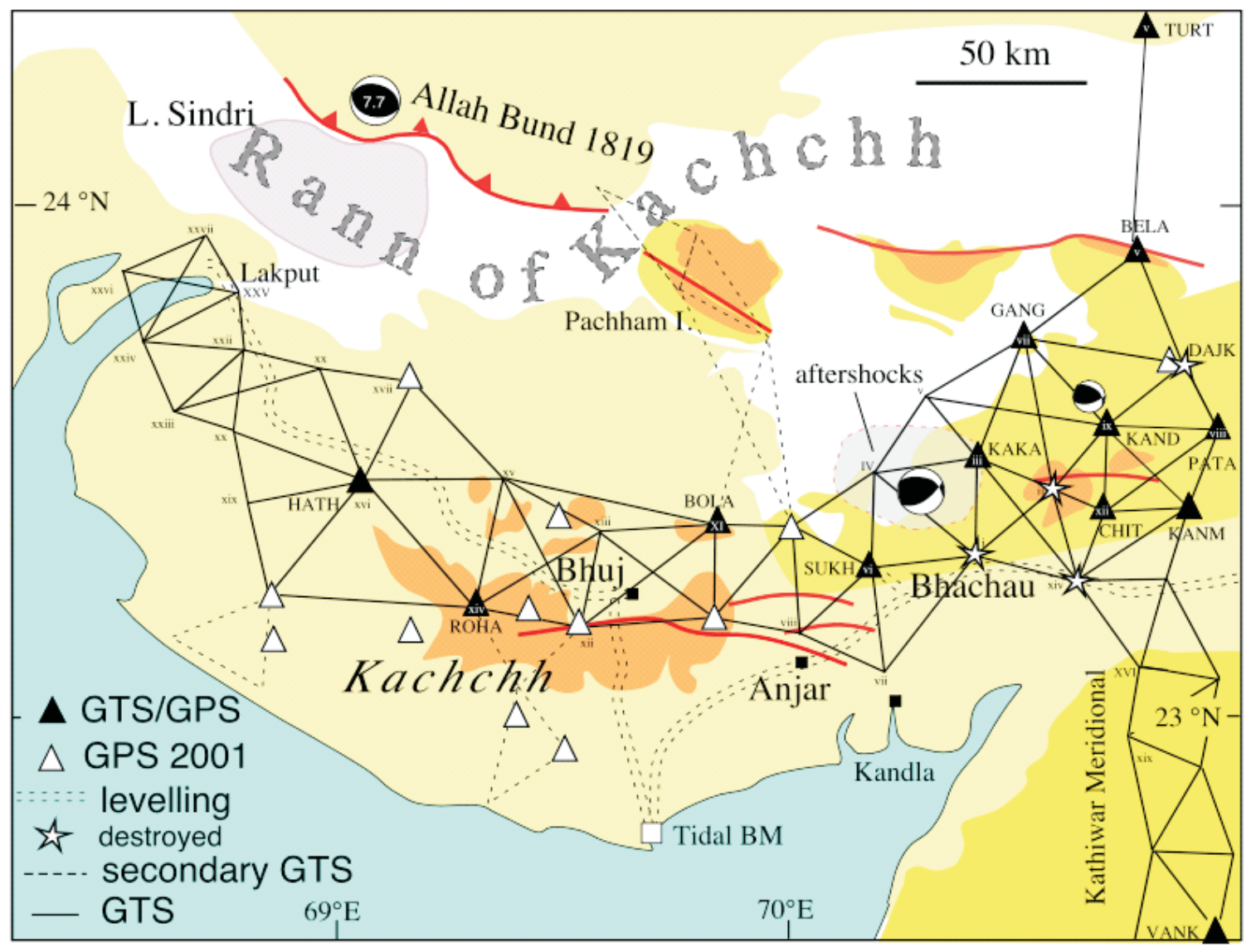

Figure 1. Location map with faults and the points measured.

figure 2). Additional GPS measurements were also completed in the epicentral region by other investigators that are not discussed in this report (Bendick et al 2001). In July 2001 sixteen additional 19th century GTS points and one new point were measured (figure 2) and the February measurements repeated. In total, sixteen GTS points were ultimately recovered (figure 2 and table 1 ). One GPS point at Jamnagar (figure 2), $150 \mathrm{~km}$ south of the epicenter and initially measured in February 1997, provides a 4-year estimate of strains related to the Bhuj earthquake just south of the KRB. This point was re-measured both in February and July 2001.

\section{Discussion of errors}

Errors in the original triangulation survey exceed errors in the GPS surveys (table 2) in 2001 by at least an order of magnitude. The 19th century errors consist of random observational errors, systematic network errors, and random motions of the trigonometrical points since then. Perhaps the largest source of uncertainty in the current analysis is that we are using the original 1860 position coordinates, and there is considerable evidence that the points have been repaired or possibly reconstructed in offset positions in the 20th century. Deformation of the Kachchh region has also occurred in the form of interseismic strain applied to the region and its release in earthquakes that occurred between 1856 and 2000 .

Observational errors were assessed at the time of publication of the 1860 GTS surveys (Burrard 1889): angular errors were assessed directly from triangle-closure statistics, and scale errors were assessed by comparing the length of a baseline with its triangulated length inferred from a baseline measured at the remote end of the network. The absolute scale accuracy is limited to roughly $10 \mathrm{ppm}$ by uncertainties in calibration of the Indian foot and its derivative length standards.

A baseline was measured SE of the epicentral region in the mid 20th century (Gulatee 1950) but the details of this measurement have not been published. Nineteenth-century scale errors dispersed throughout the north-south Kathiawar survey were estimated to be $26.4 \mathrm{~mm} / \mathrm{km}$ based on the comparison of baselines measured $211 \mathrm{~km}$ apart (Burrard 1889). In the east-west Kachchh survey the errors amounted to $72.7 \mathrm{~mm} / \mathrm{km}$ over a $560 \mathrm{~km}$ distance. These were atypically large errors compared 
Table 1. Observation duration (days) in February and July 2001, and approximate location and height of control points measured in 2001. Roman numerals (X) indicate GTS points established in c.1860, $\left(\mathrm{X}_{\mathrm{kms}}\right)=$ Kattywar Meridional Series, $\left(\mathrm{X}_{\mathrm{ccs}}\right)=$ Cutch Coast Series (Cole 1890). Trigonometrical heights are in Indian feet to the top of the original GTS pillar (the height of each pillar in feet is given in parenthesis). In cases where the original mark was not found the first epoch is given as 2001 and the GPS height is given as WGS84 geoidal height in metres corrected for antenna offset. It is known that seven GTS stations $(*)$ were re-measured and possibly repaired in 1949 (Gulatee 1950) but these data are unavailable to the present study. The $4 \mathrm{~m}$ tower at Kanduka collapsed in the earthquake but the lower point was undamaged. The 1860 metric to Indian-inch conversion is $2.5399772 \mathrm{~cm}=1$ inch.

\begin{tabular}{|c|c|c|c|c|c|c|c|c|}
\hline No. & Station name & Name & Lat. ${ }^{\circ} \mathrm{N}$ & Long. ${ }^{\circ} \mathrm{E}$ & Height & Epoch \#1 & February & July \\
\hline 1 & Bela $\left(V_{\mathrm{kms}}\right)$ & BELA & 23.90 & 70.76 & $758(5)^{\prime}$ & 1856 & - & 2.67 \\
\hline 2 & Bela east (new) & BELE & 23.89 & 70.81 & $-34.5 \mathrm{~m}$ & 2001 & 3 & 3 \\
\hline 3 & Boladi $\left(\mathrm{XI}_{\mathrm{ccs}}\right)^{*}$ & BOLA & 23.37 & 69.81 & $978(5)^{\prime} / 247.4 \mathrm{~m}$ & 1855 & - & 3 \\
\hline 4 & Charakda (new) & CHAR & 23.15 & 69.98 & $74.07 \mathrm{~m}$ & 2001 & 3 & 3 \\
\hline 5 & Chitrod $\left(\mathrm{XI}_{\mathrm{kms}}\right)^{*}$ & CHIT & 23.39 & 70.68 & $490(5 p ?)^{\prime}$ & 1854 & - & 1.64 \\
\hline 6 & Dajka (new) & DAJK & 23.69 & 70.83 & -11.6461 & 2001 & 3 & 3 \\
\hline 7 & Dajka $\left(\mathrm{VI}_{\mathrm{kms}}\right.$ destroyed) & DAJE & 23.67 & 70.81 & $126(0)^{\prime}$ & $1949 ?$ & - & 0.44 \\
\hline 8 & Faradi (new) & FARA & 22.93 & 69.51 & $13.8 \mathrm{~m}$ & 2001 & 1 & 3 \\
\hline 9 & Gangta $\left(\mathrm{VII}_{\mathrm{kms}}\right)$ & GANG & 23.74 & 70.50 & $210.7(5)^{\prime}$ & 1856 & & 0.21 \\
\hline 10 & Hathria $\left(\mathrm{XVI}_{\mathrm{ccs}}\right)$ & HATR & 23.45 & 69.05 & $696.3(5)^{\prime} / 163 \mathrm{~m}$ & 1855 & 3 & 3 \\
\hline 11 & Jamnagar & JAMN & 22.47 & 70.01 & $10 \mathrm{~m}$ & 1997 & 3 & 3 \\
\hline 12 & Kakarwa $\left(\mathrm{III}_{\mathrm{ccs}}\right)^{*}$ & KAKA & 23.49 & 70.39 & $465(5)^{\prime} / 92.2 \mathrm{~m}$ & 1857 & - & 4.32 \\
\hline 13 & Kanduka ( $\left.\mathrm{IX}_{\mathrm{kms}}\right)$ & KAND & 23.56 & 70.69 & $468(12)^{\prime}$ & 1856 & - & 0.85 \\
\hline 14 & Kanmer $\left(\mathrm{X}_{\mathrm{kms}}\right)^{*}$ & KANM & 23.39 & 70.87 & $304.5(5)^{\prime} / 41.6 \mathrm{~m}$ & 1854 & - & 3 \\
\hline 15 & $\operatorname{Kharsar}\left(\mathrm{II}_{\mathrm{kms}}\right)$ & TURT & 24.57 & 70.79 & $498(2)^{\prime}$ & 1856 & - & 2.49 \\
\hline 16 & Khalunjar $\left(\mathrm{III}_{\mathrm{kms}}\right)$ & KHAR & 24.34 & 70.76 & $1169(0)^{\prime}$ & 1856 & - & 2.18 \\
\hline 17 & Khatrod (new) & КНАТ & 23.18 & 69.80 & $294.7 \mathrm{~m}$ & 2001 & 3 & 3 \\
\hline 18 & Khoj (new) & KHOJ & 23.01 & 69.41 & $60.0 \mathrm{~m}$ & 2001 & 1 & 3 \\
\hline 19 & Manava $\left(\mathrm{XXXVII}_{\mathrm{kms}}\right)$ & MANA & 21.36 & 71.09 & $815(5)^{\prime}$ & 1853 & - & 1.84 \\
\hline 20 & Nagar Ghantiarno (new) & NAGR & 24.32 & 70.79 & $21.2 \mathrm{~m}$ & 2001 & - & 1.33 \\
\hline 21 & Pata-i-Shah (VIII $\left.{ }_{\text {kms }}\right)$ & PATA & 23.56 & 70.94 & $284(5)^{\prime} / 35.9 \mathrm{~m}$ & 1854 & - & 4.15 \\
\hline 22 & Roha hill $\left(\mathrm{XIV}_{\mathrm{ccs}}\right)$ & ROHA & 23.20 & 69.27 & $875(4)^{\prime}$ & 1855 & - & 3 \\
\hline 23 & Sackpur $\left(\mathrm{XXXVI}_{\mathrm{kms}}\right)$ & SACK & 21.56 & 71.51 & $634(1)^{\prime}$ & 1853 & - & 1.33 \\
\hline 24 & Samatra (new) & SAMA & 23.19 & 69.47 & $142.7 \mathrm{~m}$ & 2001 & 1 & 3 \\
\hline 25 & Sukhpur $\left(\mathrm{VI}_{\mathrm{ccs}}\right)^{*}$ & SUKH & 23.28 & 70.16 & $357.2(5)^{\prime} / 556.8 \mathrm{~m}$ & 1857 & - & 5.27 \\
\hline 26 & Vankaner $\left(\mathrm{XXIV}_{\mathrm{kms}}\right)$ & VANK & 22.60 & 70.93 & $601(5)^{\prime}$ & 1853 & - & 1.91 \\
\hline
\end{tabular}

to other branches of the Great Trigonometrical Survey. The line lengths in the vicinity of the Bhuj earthquake are of the order of $20-30 \mathrm{~km}$ so that uncertainties in position of contiguous points could be as large as $2.2 \mathrm{~m}$ in longitude and $0.8 \mathrm{~m}$ in latitude. These errors are significant compared to anticipated co-seismic displacements and place significant constraints on our ability to make direct comparisons between 19th century GTS and 20th century GPS line lengths.

In contrast, angular errors estimated from triangle closure observations are small. Mean angular errors in the two surveys were estimated to be 1.1 and $1.3 \mu \mathrm{rad}$ respectively (DeGraaff Hunter 1918), and the density of points at the confluence of the Kathiawar and Kachchh surveys provide unusually good geometry for the suppression of random angular errors (Burrard 1889). Triangle misclosure errors for the original triangulation listed by Cole (1890) are as low as $0.8 \mu \mathrm{rad}$ to as high as $3 \mu \mathrm{rad}$ in the epicentral region, corresponding to maximum errors in relative angular position of $10 \mathrm{~cm}$ in the $30 \mathrm{~km}$-long lines near the epicenter.

We next discuss the characteristics of systematic reference frame errors in the GTS survey network. This is necessary because the parameters of the Everest Spheroid to which the GTS point positions were reduced are an imperfect description of their actual positions. This is partly because imprecise sea-level heights were used to correct line-lengths and partly because, for the same reason, spherical triangles were incorrectly corrected for spherical excess (DeGraaff Hunter 1918), and although this has a trivial effect in terms of relative posi- 


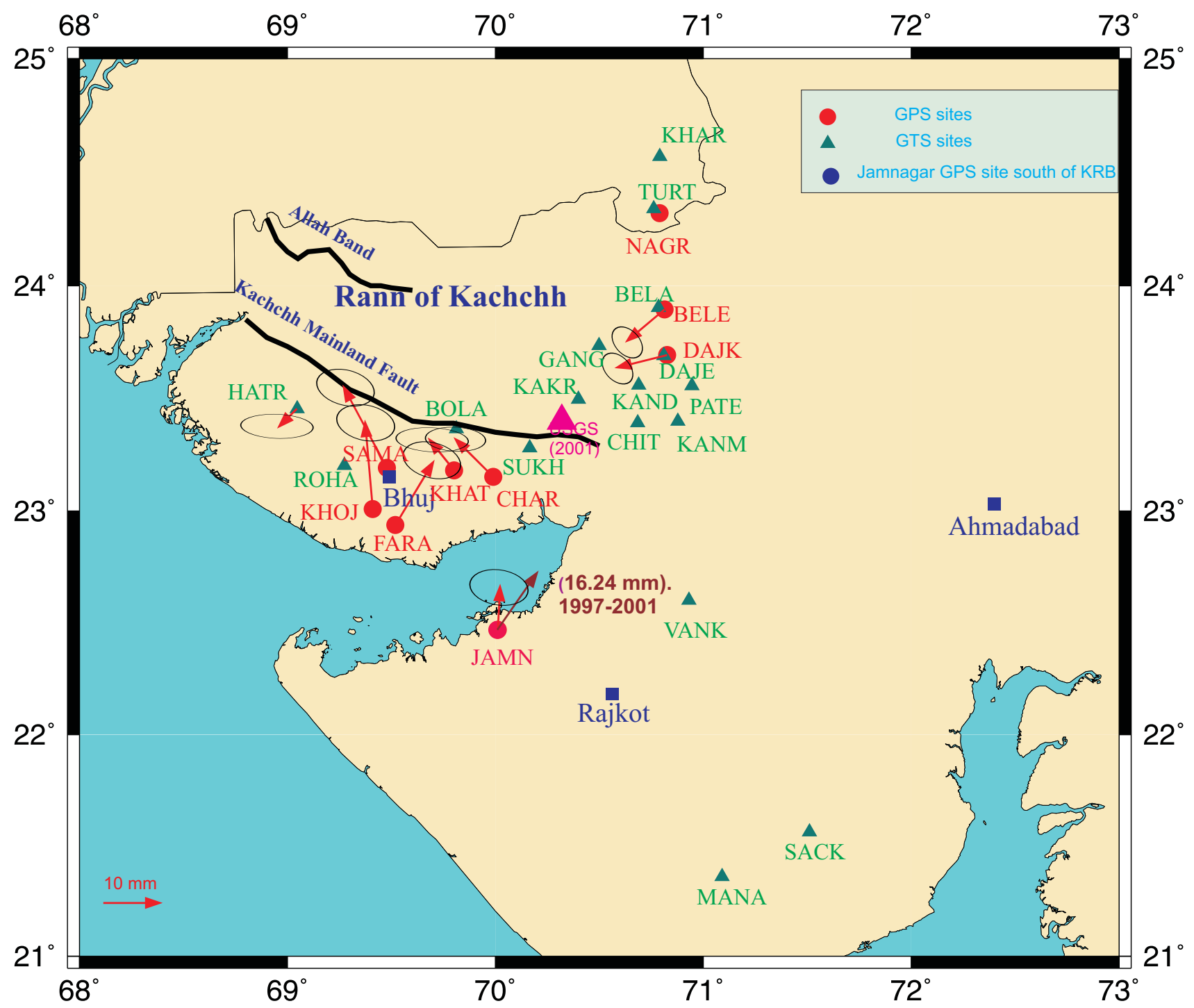

Figure 2. Sites measured using GPS geodesy and the GPS derived co-seismic and post seismic vectors with associated error ellipses.

tions within the epicentral area it causes coordinates to deviate in ways that cannot be corrected using a simple coordinate transform. Other systematic errors were introduced by not knowing the deflection-of-the-vertical at every trigonometrical point.

The original survey measured heights using triangulation, but these were corrected subsequently by spirit leveling from tide gauges. For example leveling in 1923 required heights in the Kachchh region to be adjusted by 30-60 cm (Gwyn 1928).

Over a relatively small area, such as that overlying the Kachchh epicenter, the published coordinates contain errors that take the form of an approximately uniform shift in scale, position, and rotation of the true Everest Spheroid coordinates. A simple transformation of the published GTS coordinates to a GPS WGS84-based frame of ref- erence, reveals apparent shifts in position resulting from imperfectly known transformation parameters. This form of error can be considered noise that contains no tectonic information. In order to reveal true displacements between the two surveys the investigator has no alternative but to minimize scale, rotation and position errors numerically after coordinate transformation. The minimization is typically undertaken using least-squares methods to minimize changes in positions outside the area known to have been deformed by the earthquake.

We describe below a direct least-squares adjustment that assumes no a priori information about the frames of reference of the coordinates to estimate 2001-1859 coordinate changes. We follow this with a second approach in which we execute a formal transformation using published spheroid and geoid parameters to calculate base line changes. 


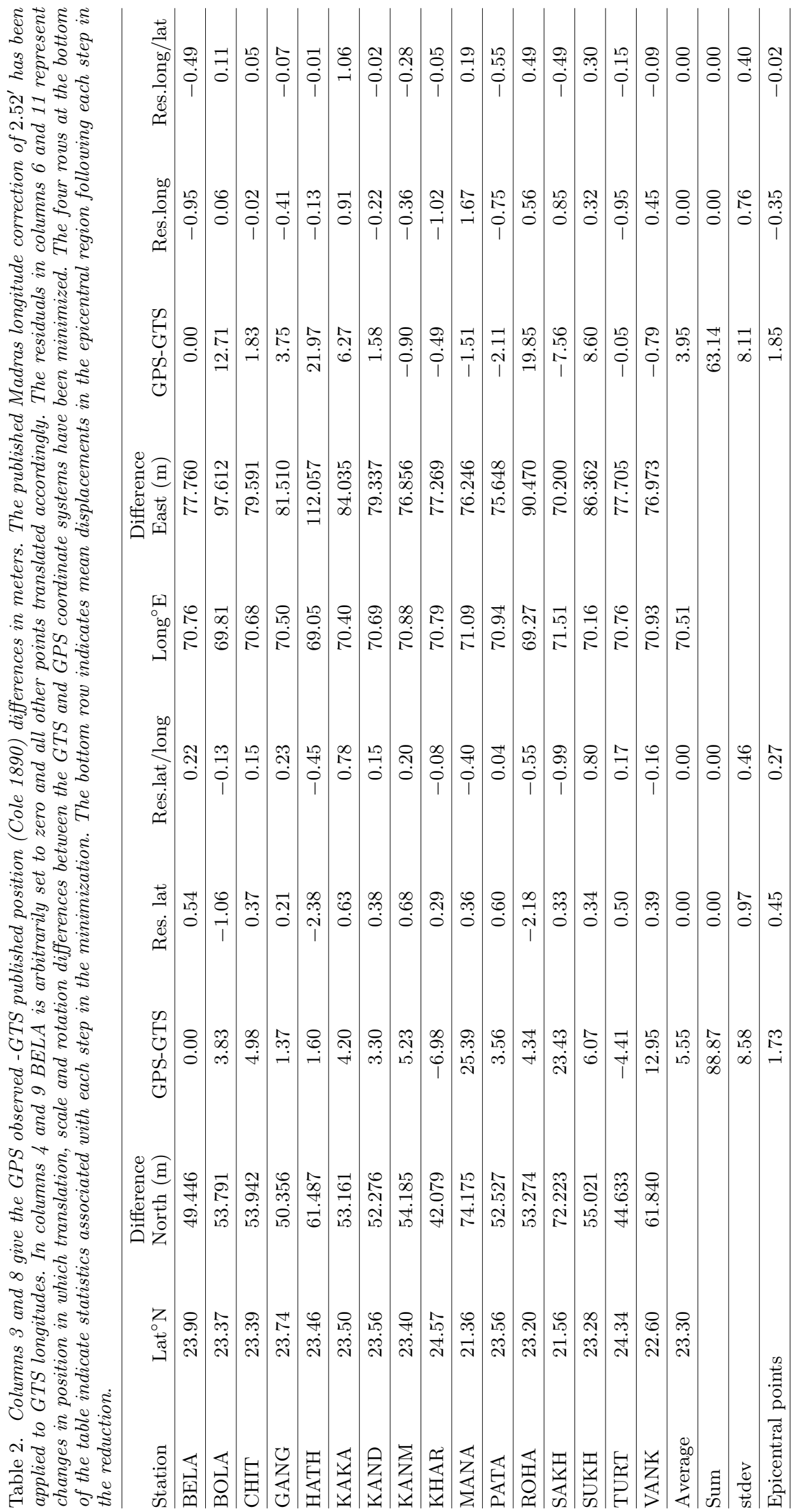




\section{Data analysis and results}

\subsection{GPS data}

The GPS data were analyzed using Bernese 4.2, with ambiguities fixed, in an India fixed reference frame. These methods have been described elsewhere (Jade et al 2002). Subsets of the data were processed by two independent groups, and calculated positions were compared after analysis. Differences between the two solutions were found to be less than $5 \mathrm{~mm}$.

\subsection{Pre-seismic strain}

Although triangulation re-measurements of GTS points near the epicenter prior to the earthquake were made in 1949 (Gulatee 1950) we are unaware of published data from this re-survey. Measurements of the leveling line through the Kachchh mainland that were made after the Anjar earthquake (Chung and Gao 1995) show uplift of the order of $1 \mathrm{~m}$ but these are unavailable in a form that permits precise analysis (Nagar and Singh 1992). The association of significant vertical deformation with the Anjar earthquake indicates that an analysis of the Bhuj earthquake first requires the inferred deformation of the Anjar event to be removed.

GPS measurements at Jamnagar (figure 2) in 1997, four years prior to the earthquake provide an upper limit for recent pre-seismic strain rates near the epicenter. The GPS derived displacement vector at Jamnagar (figure 2) for the period, February 1997 to February 2001 is $16 \pm 8 \mathrm{~mm}$ at $\mathrm{N} 35^{\circ} \mathrm{E}$ (Jade et al 2002). This is consistent with elastic models of the Bhuj earthquake developed below that suggest that displacements of up to $2 \mathrm{~cm}$ may have occurred at this location, and indicates that preseismic strain rates applied to the Kachchh region were not excessive compared to those prevailing in central India. We address this issue in a following section.

\subsection{Changes in GTS-GPS positions 1860-2001 - Least-squares analysis}

In view of the uncertainties in a rigorous transformation between published Everest Spheroid positions and WGS84 discussed above we first apply a direct least-squares approach to extracting coseismic displacements from the pre-seismic and post-seismic data. This is made possible by the availability of data measured more than $150 \mathrm{~km}$ from the epicenter, where earthquake related deformation (from the Bhuj 2001 event) is small relative to observational errors. The data span a
$300 \mathrm{~km}$ north-south distance and a $250 \mathrm{~km}$ eastwest distance. By minimizing mean scale, rotation and translation differences between coordinates for the entire array we reveal anomalous changes in the central part of the re-measured array near the epicenter. The approach not only avoids invoking uncertain transformation parameters, but it also removes homogeneous strain and displacement effects in the epicentral region resulting from interseismic tectonic deformation. The residual displacement field should thus characterize heterogeneous deformation within the field of interest, in particular the deformation caused by the occurrence of the Anjar 1956 and Bhuj 2001 earthquakes. In the following analysis it has been possible to identify points that have been reconstructed historically in misplaced positions. Such points have been ignored in the following analysis.

The analysis proceeds as follows: we first subtract the published GTS coordinate from the calculated GPS coordinate. This value is meaningless since it does not take into account the different coordinate systems. Its mean numerical difference for all latitude positions is $7 \pm 8.6 \mathrm{~m}$ after setting the resulting north coordinate change of BELA to zero, and subtracting this latitude shift from all points in the array (table 2). We then plot a graph of latitude vs. latitude-change (GPS-GTS coordinate converted to meters) and obtain a slope and offset for a least-squares regression fit to the data (figure 3a). The slope and offset of the linear fit is caused by the difference in parameters used in the WGS84 and Everest spheroids, with a contribution from geoid slope. These parameters are not of interest. We thus subtract from the data the parameters of the least-squares fit to obtain a plot of residuals. The mean difference in position is now $0 \pm 0.97 \mathrm{~m}$, indicating that we have minimized the translation error between the GTS and GPS surveys, and that the scatter in positions resulting from the scale difference between the two surveys has been reduced by an order of magnitude.

We then examine whether there exists any residual correlation between longitude and the residual latitude change (figure $3 \mathrm{~b}$ ). The mean northerly displacement and standard deviation of point positions following this second regression analysis are $0 \pm 0.46 \mathrm{~m}$. This analysis of latitude changes revealed that points west of the epicenter increasingly move southward. Points east and SE of the epicenter do not show a distinct correlation with longitude. The effect is quite large with epicentral points being displaced on an average by less than $+45 \mathrm{~cm}$ whereas three western points BOLA, ROHA and HATH are shifted southward $1.1 \mathrm{~m}, 2.2 \mathrm{~m}$ and $2.4 \mathrm{~m}$ respectively. This is possibly caused by a rotation artifact between the coordinates in the Kachchh series and the Katty- 

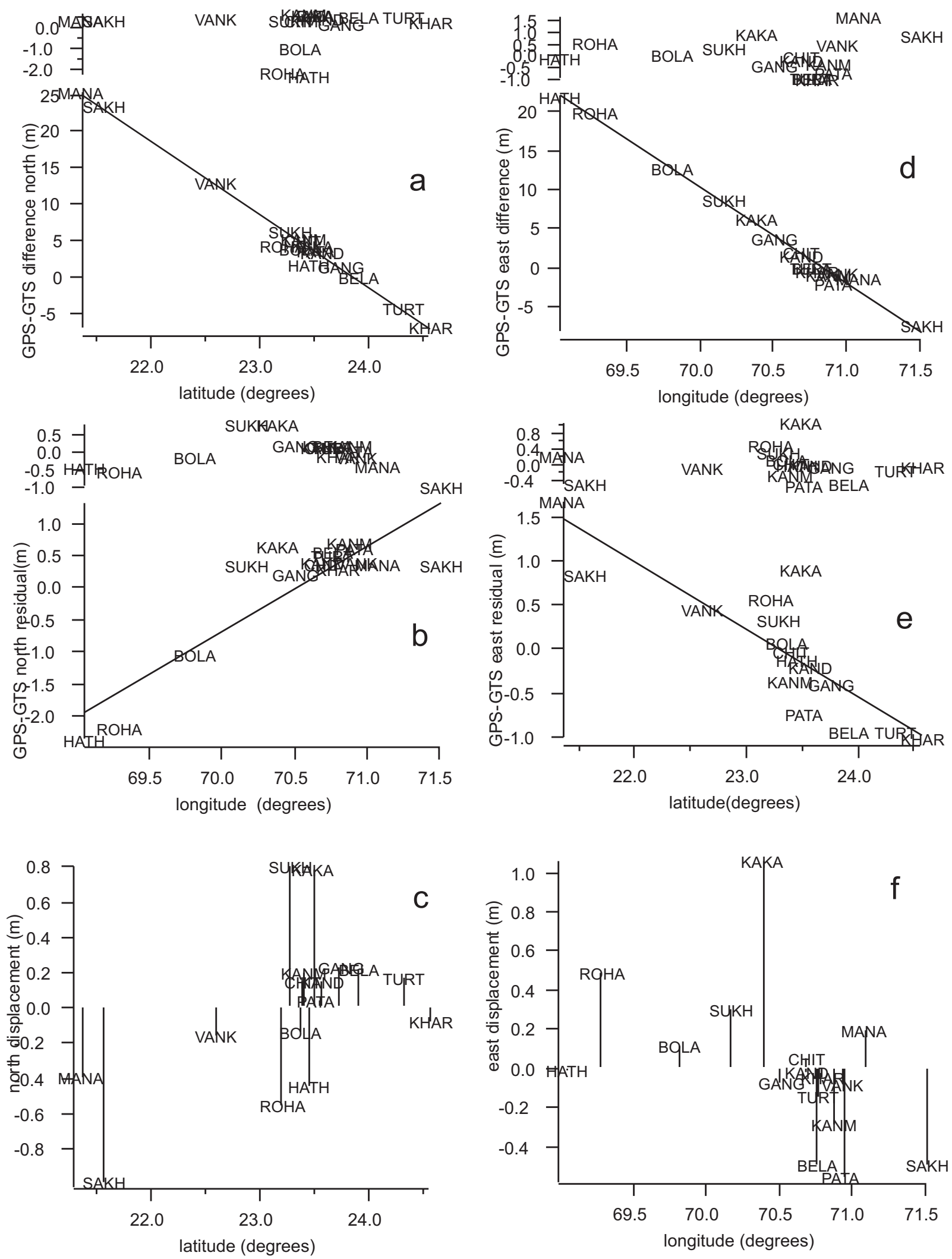

Figure 3. Co-seismic data processing sequence. The top two panels graph differences between observed GPS (WGS84) and historic GTS (Everest Spheroid) data, and differences from least-squares fits to these data. The central panel regresses these residuals against the orthogonal component of their positions, and obtains a second pair of residual displacements in each component. These final residuals are plotted in the bottom panels as displacements from the average position of all points in their respective components. The vertical lines represent anomalous displacements in the epicentral region where scale, rotation and displacement differences between the two surveys have been minimized. 
Table 3. Calculated GPS and GTS baseline lengths between station pairs and associated strain changes in part per million. Strain rates in micro-strain per year is also given in the table assuming uniform strain.

\begin{tabular}{|c|c|c|c|c|}
\hline Station pair & GPS distance $(\mathrm{m})$ & 1856 Dist $(\mathrm{m})$ & $\begin{array}{l}\text { XYZ Calc strain } \\
(\mathrm{ppm})\end{array}$ & Strain rate \\
\hline PATA-KAKA & 56042.7092 & 56044.0278 & -23.5 & -0.2 \\
\hline KAKA-KANM & 50025.8465 & 50026.9216 & -21.5 & -0.1 \\
\hline KANM-SUKH & 74095.1345 & 74095.3209 & -2.5 & 0.0 \\
\hline HATH-BOLA & 78867.4255 & 78867.0551 & 4.7 & 0.0 \\
\hline BOLA-KHAR & 166809.5586 & 166811.7403 & -13.1 & -0.1 \\
\hline KHAR-BELA & 74142.6689 & 74144.6887 & -27.2 & -0.2 \\
\hline BELA-GANG & 32262.5449 & 32262.6635 & -3.7 & 0.0 \\
\hline GANG-KAND & 27464.8970 & 27464.9311 & -1.2 & 0.0 \\
\hline KAND-CHIT & 18622.4801 & 18622.6632 & -9.8 & -0.1 \\
\hline CHIT-VANK & 91089.7165 & 91090.4479 & -8.0 & -0.1 \\
\hline PATA-KANM & 18919.3972 & 18919.6763 & -14.8 & -0.1 \\
\hline KAKA-SUKH & 33898.1306 & 33897.4605 & 19.8 & 0.1 \\
\hline SUKH-HATH & 115937.6070 & 115937.1704 & 3.8 & 0.0 \\
\hline HATH-KHAR & 216463.1273 & 216464.8908 & -8.1 & -0.1 \\
\hline BOLA-BELA & 113416.8121 & 113416.3464 & 4.1 & 0.0 \\
\hline KHAR-GANG & 97373.4365 & 97375.9557 & -25.9 & -0.2 \\
\hline BELA-KAND & 38637.6437 & 38637.8225 & -4.6 & 0.0 \\
\hline GANG-CHIT & 42448.2999 & 42448.5425 & -5.7 & 0.0 \\
\hline KAND-VANK & 108952.0907 & 108953.0098 & -8.4 & -0.1 \\
\hline PATA-SUKH & 85423.4996 & 85423.9402 & -5.2 & 0.0 \\
\hline KANM-HATH & 187285.5020 & 187284.8650 & 3.4 & 0.0 \\
\hline SUKH-BOLA & 37263.6319 & 37263.6295 & 0.1 & 0.0 \\
\hline HATH-BELA & 181453.9266 & 181452.8077 & 6.2 & 0.0 \\
\hline BOLA-GANG & 81249.4374 & 81248.8571 & 7.1 & 0.0 \\
\hline KHAR-KAND & 112557.3919 & 112560.3073 & -25.9 & -0.2 \\
\hline BELA-CHIT & 57118.5989 & 57118.9431 & -6.0 & 0.0 \\
\hline GANG-VANK & 133084.6175 & 133085.6188 & -7.5 & -0.1 \\
\hline KAKA-HATH & 138378.9120 & 138376.9802 & 14.0 & 0.1 \\
\hline KANM-BOLA & 109054.5462 & 109054.3146 & 2.1 & 0.0 \\
\hline SUKH-KHAR & 156630.2851 & 156634.1053 & -24.4 & -0.2 \\
\hline HATH-GANG & 151472.1610 & 151471.0040 & 7.6 & 0.1 \\
\hline BOLA-KAND & 92264.6151 & 92264.0473 & 6.2 & 0.0 \\
\hline KHAR-CHIT & 131147.0568 & 131150.3975 & -25.5 & -0.2 \\
\hline BELA-VANK & 145188.4645 & 145189.4435 & -6.7 & 0.0 \\
\hline PATA-HATH & 194241.3099 & 194240.6325 & 3.5 & 0.0 \\
\hline KAKA-BOLA & 61857.0483 & 61855.4540 & 25.8 & 0.2 \\
\hline KANM-KHAR & 130355.7481 & 130359.4418 & -28.3 & -0.2 \\
\hline SUKH-BELA & 91733.9183 & 91734.5611 & -7.0 & 0.0 \\
\hline HATH-KAND & 168248.6495 & 168247.6228 & 6.1 & 0.0 \\
\hline BOLA-CHIT & 89266.4014 & 89265.9659 & 4.9 & 0.0 \\
\hline KHAR-VANK & 218589.6078 & 218595.0231 & -24.8 & -0.2 \\
\hline PATA-BOLA & 117711.9365 & 117711.7321 & 1.7 & 0.0 \\
\hline KAKA-KHAR & 125650.1428 & 125653.8148 & -29.2 & -0.2 \\
\hline KANM-BELA & 57344.1147 & 57344.5836 & -8.2 & -0.1 \\
\hline SUKH-GANG & 60803.6788 & 60804.2748 & -9.8 & -0.1 \\
\hline
\end{tabular}


Table 3. (Continued)

\begin{tabular}{|c|c|c|c|c|}
\hline Station pair & GPS distance (m) & 1856 Dist (m) & $\begin{array}{l}\text { XYZ Calc strain } \\
(\mathrm{ppm})\end{array}$ & Strain rate \\
\hline HATH-CHIT & 167554.9192 & 167554.0830 & 5.0 & 0.0 \\
\hline BOSLA-VANK & 142700.0887 & 142700.9810 & -6.3 & 0.0 \\
\hline PATA-KHAR & 113495.9867 & 113499.2841 & -29.1 & -0.2 \\
\hline KAKA-BELA & 57972.5897 & 57973.8189 & -21.2 & -0.1 \\
\hline KANM-GANG & 53788.7379 & 53789.1602 & -7.9 & -0.1 \\
\hline SUKH-KAND & 61951.3824 & 61951.6138 & -3.7 & 0.0 \\
\hline HATH-VANK & 215242.5856 & 215243.2243 & -3.0 & 0.0 \\
\hline PATA-BELA & 42877.0546 & 42877.3240 & -6.3 & 0.0 \\
\hline KAKA-GANG & 28309.5624 & 28310.5216 & -33.9 & -0.2 \\
\hline KANM-KAND & 26331.3005 & 26331.7102 & -15.6 & -0.1 \\
\hline SUKH-CHIT & 54578.7454 & 54578.7732 & -0.5 & 0.0 \\
\hline PATA-GANG & 49600.76378 & 49601.10081 & -6.8 & 0.0 \\
\hline KAKA-KAND & 30407.81166 & 30408.8268 & -33.4 & -0.2 \\
\hline KANM-CHIT & 19788.93813 & 19789.14045 & -10.2 & -0.1 \\
\hline SUKH-VANK & 108931.2937 & 108931.6989 & -3.7 & 0.0 \\
\hline PATA-KAND & 26061.59748 & 26061.97284 & -14.4 & -0.1 \\
\hline KAKA-CHIT & 31257.24231 & 31257.98656 & -23.8 & -0.2 \\
\hline KANM-VANK & 88240.44233 & 88240.94078 & -5.6 & 0.0 \\
\hline PATA-CHIT & 32277.34941 & 32277.68124 & -10.3 & -0.1 \\
\hline KAKA-VANK & 113067.4722 & 113068.3769 & -8.0 & -0.1 \\
\hline PATA-VANK & 105697.3925 & 105698.1252 & -6.9 & 0.0 \\
\hline
\end{tabular}

war series, or it may be real displacement associated with deformation of the Katrol Hill fold belt, either by creep or during historic earthquakes. The removal of the longitude correlation with latitude shift thus brings with it the possibility that we may be adding noise to the Bhuj 2001 deformation signal. Figure 3(c) shows the northerly difference in point positions as a function of latitude.

The above procedure is then repeated for longitude versus observed change-in-longitude (figure $3 \mathrm{~d}$ ). In this case the large offset between the two coordinate systems caused by the known error in the adopted position for the longitude of Madras (2.52' east of its true position) is first removed, and displacements calculated by setting the displacement at BELA to zero as before (table 2). The initial differenced positions reveal an average displacement in longitude of $3.9 \pm 8.1 \mathrm{~m}$. The residuals following a least squares regression of longitude vs. change-in-longitude are $0 \pm 0.76 \mathrm{~m}$. Finally we regressed longitude residuals against latitude and determined a new set of residuals with an average "co-seismic" longitude displacement of $0 \pm 0.4 \mathrm{~m}$ (figure 3e). Figure $3(\mathrm{f})$ shows the easterly difference in point positions as a function of longitude.

An alternative approach to the above described least-squares minimization scheme is to assume that selected points outside the area affected by the earthquake have not changed in relative position. This brings with it the danger of biasing epicentral displacements by forcing them to conform to shifts in specific survey points outside the epicentral region resulting either from earlier earthquakes or from random instability of the 1860 pillars. The effects of biasing individual points can be reduced by adopting the least squares analysis approach described above, and by weighting external points more heavily in the analysis.

\subsection{Changes in GTS-GPS positions 1860-2001 - Coordinate transform analysis}

In this section we calculate a formal coordinate transformation of the GTS coordinate positions in order to determine changes in line lengths between the GPS-2001 and GTS-1860 measurements. The line length changes are independent of translation and rotation errors but may contain errors introduced by uncertainties in some of the transformation parameters, notably by scale errors in the original survey.

The published GTS longitudes were corrected as before for the known 2.52' longitude offset. Next the published mean-sea-level heights were 
adjusted to International Spheroid heights using Chart XXIII of the Survey of India geoid map (e.g. Survey of India, 1950). In the absence of detailed geoid information we applied a $+10 \mathrm{~m}$ shift to published heights. These International spheroid heights were referenced to the Everest spheroid using methods outlined by Gulatee (1935). The resulting north, east and height Everest Spheroidal GTS coordinates were converted to Cartesian coordinates using the following transformation parameters:

Semi major axis $=6377276 \mathrm{~m}$, Flattening $=$ $300.8017 \mathrm{~m}, \mathrm{Tx}=286.0364 \mathrm{~m}, \mathrm{Ty}=710.0388 \mathrm{~m}$, $\mathrm{Tz}=247.2654 \mathrm{~m}$. (see Blume 1999 for the derivation of these numbers.)

The GPS north, east and height data were also converted to a Cartesian system and straight line distances calculated between station pairs for both the GTS lengths and the GPS line lengths. Differences between the two pairs of line lengths are listed in table 3 as strain changes in part per million. The table also lists strain rates in micro-strain per year assuming uniform strain.

For comparison purposes we show strain changes derived from the least squares analysis method and from the formal transformation method in figure 4 . Figure 4 shows the expected absence of regional strain in the least squares reduction compared to the transformation method. In the first we assume no net strain in the region and effectively force it to be zero. In contrast, the transformation method makes no such assumption and reveals real strain changes with the primary assumption that we know the scale of the original survey.

\subsection{Strain changes 1860-2001}

We note that strain contraction (figure 4) in the coordinate transform comparison is five times higher across the Rann of Kachchh than strain contraction in the Kathiawar Peninsula. Because of the scale uncertainties of the original survey, the absolute values of these strains are close to or below the noise level. However, the relative strain change is persuasive since this depends more on the angular accuracy of the triangulation (an analysis of angular strain changes is relegated to a future article). If we make the reasonable assumption that the Kathiawar Peninsula has remained stable in this time interval we conclude that the Rann of Kachchh may have contracted by $8-10 \mathrm{~mm} /$ yr. uniformly in the past 140 years, or that earthquakes and interseismic strain between 1860 and 2001 resulted in $1-1.3 \mathrm{~m}$ of contraction. Post-seismic adjustment following the November 1856 earthquake that occurred during the measurement of the Kathiawar Series may have contributed to this convergence, but published reports do not specify which of the triangles were distorted and required re-measurement in 1856.

In both analyses, surface strain changes (figure 4 ) in the epicentral region exceed $25 \mu$-strain in extension of the hanging wall and $33 \mu$-strain in contraction of the quadrant that includes the footwall of the rupture zone. Maximum line length changes are concentrated in the region above the aftershock zone.

\subsection{Inferred co-seismic displacements}

Two large displacements dominate the result (point BELA is held fixed in figure 5 and table 2): the $1.05 \mathrm{~m}$ eastward movement of KAKA and the $0.55 \mathrm{~m}$ westward movement of PATA. The remaining seven GTS points within $40 \mathrm{~km}$ of the epicenter have moved by less than $1 \mathrm{~m}$ and many of them much less. Relative motions between contiguous points are typically less than $50 \mathrm{~cm}$ with errors of the order of 10-20 cm (assuming a maximum angular error of $3 \mu \mathrm{rad}$ between contiguous points).

We assume that the observed displacements result from slip on a single buried dislocation and proceed to estimate the slip parameters of the main shock. As a starting point we use the teleseismic mechanism published by Anatoli (2001) constrained by aftershock locations recorded by local networks (Bodin et al 2001; Sato et al 2001). We used boundary element models originally developed by G. C. P. King and recently coded by Toda et al (1998) within the Coulomb 2.1 software package to compare measured and estimated surface displacements from a number of possible rupture parameters for the earthquake.

A number of forward models were able to reproduce the approximate distribution of surface displacements observed in the earthquake. A dip of $45^{\circ}$ on a $40 \mathrm{~km}$ long rupture zone between 9 and $35 \mathrm{~km}$ depth was found to give a reasonable fit to the data. The models tested assumed uniform slip and with a slip of $6-10 \mathrm{~m}$. The best fitting models required a slip of $6 \mathrm{~m}$ suggesting that the slip on the rupture was approximately twice the mean slip estimated from teleseismic data. Since most of the epicentral GPS measurements were made in July 2001, six months after the earthquake, it is possible that the geodetic estimate includes substantial afterslip. In the next section we note that afterslip between 3 weeks and 6 months following the earthquake amounted to $10 \%$ of the co-seismic signal.

\subsection{Post-seismic displacements}

Seven new GPS points near the epicentre, one GTS point (Hathria) and Jamnagar (south of KRB) which were measured both in February and July, 


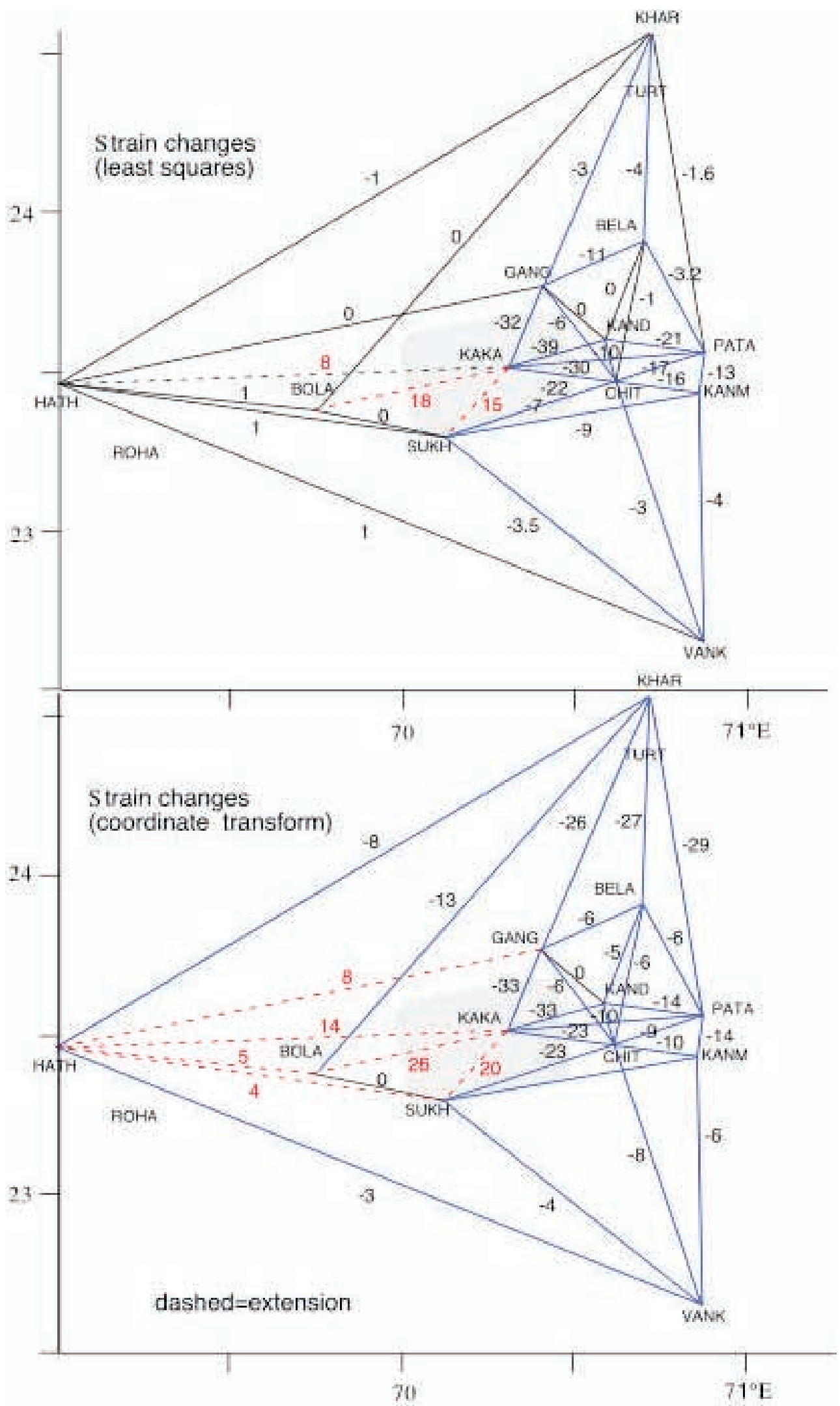

Figure 4. Line length changes derived from GPS and GTS measurements using least-squares minimization procedure, and coordinate transformation method. Overall strain changes are effectively absent outside the epicentral region in the first method ( $<3 \mu$-strain) whereas in the second method, convergence across the Rann of Kachchh $(\sim 25 \mu$-strain) contrasts with minor convergence of the Kathiawar Peninsula in the south $(\sim 6 \mu$-strain). The region of the main shock and aftershocks is indicated as a grey shaded patch. Lines that extend by more than $4 \mu$-strain are shown dashed. 


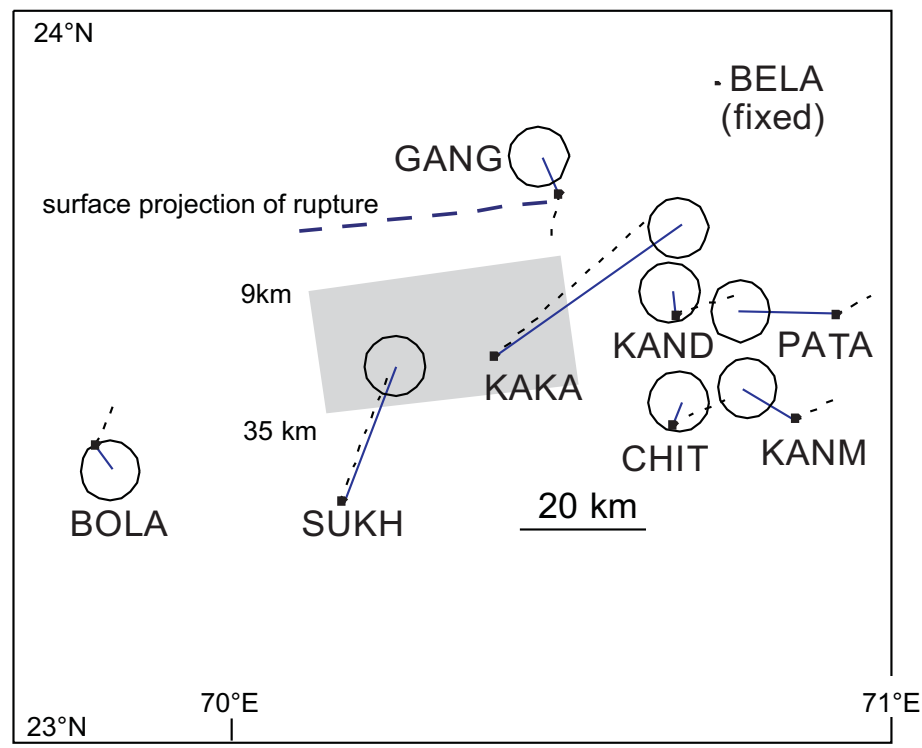

Figure 5. Co-seismic slip vectors derived from least-squares minimization analysis. Uniform uncertainties of $20 \mathrm{~cm}$ are indicated and the largest displacement vector at KAKA corresponds to $1.05 \mathrm{~m}$. Dashed lines indicate synthetic displacements assuming $6 \mathrm{~m}$ of mean subsurface slip and $1 \mathrm{~m}$ left lateral slip. The long dashed line indicates the inferred surface projection of the rupture (shaded).

2001 are associated with centering errors of the order of $1 \mathrm{~mm}$ and processing errors of less than $5 \mathrm{~mm}$ (figure 2). These data are both in the WGS84 datum and show displacements ranging from 5 to $16 \mathrm{~mm}$ (figure 2) since the Bhuj earthquake.

Table 4 lists GPS derived baseline lengths between the eight points in KRB and Jamnagar measured in February and July, 2001 along with their changes. GPS baseline length changes indicate both elongation and shortening during this five month period. These line lengths correspond to an average strain rate of $0.45 \mu$-strain/year for the six month period. Post-seismic (February - July 2001) GPS-GPS displacement vectors are available from a total of nine points and are as shown in figure 2. The February-July, 2001 GPS-GPS displacement vectors at these nine points near the epicenter indicate displacement rates averaging 1 to $2 \mathrm{~mm} /$ month. The observed post-seismic vectors are consistent with continued slip on the Bhuj rupture zone and its projections to deeper and shallower depths.

\section{Conclusions}

Despite uncertainties in 19th century reference frames, and evidence for 20th century repair and possible reconstruction of triangulation points, remeasurements near the Bhuj epicenter yield a consistent view of reverse faulting at depth with dip, strike and location similar to that calculated from teleseismic data. Assuming that uniform slip occurred on a single planar dislocation requires coseismic slip to have been $8 \pm 2 \mathrm{~m}$, i.e., a factor of two larger than the mean slip determined from teleseismic data. A more precise analysis of geodetically constrained slip will be possible following the release and publication by the Survey of India of 20th century coordinates, coordinate changes, and height changes.

Assuming that trigonometrical points have not artificially been displaced from published 19th century positions, the re-measurements suggest that the Rann of Kachchh north of the epicenter has closed by more than $1 \mathrm{~m}$ in the past 140 years. The convergence is unlikely to have been influenced by control point reconstruction since the point north of the Rann is inscribed on granite, and the numerous points south of the Rann have a low probability of having been moved ubiquitously southward during repair. It is not possible to say whether the convergence has been uniform during this time or whether it has been associated with earthquake activity in the past 140 years. The convergence is consistent with the mechanism of Bhuj 2001 earthquake and is consistent with stress azimuths measured throughout India. We note that prior to the earthquake convergence across the Rann may have attained higher values than those we measured after the earthquake, post-seismic surface displacements indicate that aftershock activity continued to permit NE/SW contraction in the months following the earthquake. 
Table 4. GPS baseline lengths $(L \mathrm{~km})$ and changes $(\Delta L \pm 4.5 \mathrm{~mm})$ and associated strain between February and July 2001.

\begin{tabular}{|c|c|c|c|c|}
\hline Baseline & $\mathrm{L}, \mathrm{km}$ & $\Delta \mathrm{L}, \mathrm{mm}$ & $\mu$-strain & Azimuth $\left(^{\circ}\right)$ \\
\hline JAMN-HATR & 147.33 & -4.8 & -0.033 & 315.61 \\
\hline JAMN-CHAR & 75.583 & -0.6 & -0.008 & 358.22 \\
\hline JAMN-KHAT & 81.671 & -1.1 & -0.013 & 343.70 \\
\hline JAMN-BELE & 178.08 & -14 & -0.079 & 60.59 \\
\hline JAMN-DAJK & 159.23 & -13.1 & -0.082 & 56.32 \\
\hline JAMN-KHOJ & 85.869 & 5.8 & 0.068 & 312.00 \\
\hline JAMN-FARA & 72.422 & -2 & -0.028 & 313.58 \\
\hline JAMN-SAMA & 96.928 & 9.7 & 0.100 & 323.54 \\
\hline HATR-CHAR & 102.21 & -6.3 & -0.062 & 107.83 \\
\hline HATR-KHAT & 83.135 & -4.1 & -0.049 & 109.90 \\
\hline HATR-BELE & 186.88 & -1.7 & -0.009 & 76.02 \\
\hline HATR-DAJK & 183.66 & -3.1 & -0.017 & 82.38 \\
\hline HATR-KHOJ & 61.897 & -13.8 & -0.223 & 140.67 \\
\hline HATR-FARA & 75.012 & -4.9 & -0.065 & 137.58 \\
\hline HATR-SAMA & 52.899 & -15.2 & -0.287 & 121.42 \\
\hline CHAR-KHAT & 19.419 & -2.5 & -0.129 & 98.98 \\
\hline CHAR-BELE & 117.83 & -7.9 & -0.067 & 47.96 \\
\hline CHAR-DAJK & 104.47 & -6.5 & -0.062 & 57.09 \\
\hline CHAR-KHOJ & 61.337 & -8.6 & -0.140 & 193.80 \\
\hline CHAR-FARA & 53.759 & -14 & -0.260 & 204.44 \\
\hline CHAR-SAMA & 52.644 & 3.1 & 0.059 & 274.46 \\
\hline KHAT-BELE & 130.13 & -7.5 & -0.058 & 54.78 \\
\hline KHAT-DAJK & 119.00 & -6.8 & -0.057 & 63.42 \\
\hline KHAT-KHOJ & 44.404 & -7.5 & -0.169 & 203.67 \\
\hline KHAT-FARA & 39.672 & -11.6 & -0.292 & 220.62 \\
\hline KHAT-SAMA & 33.335 & 6 & 0.180 & 271.82 \\
\hline BELE-DAJK & 22.420 & -2.2 & -0.098 & 176.64 \\
\hline BELE-KHOJ & 173.75 & -17.3 & -0.100 & 212.26 \\
\hline BELE-FARA & 169.67 & -20.7 & -0.122 & 216.47 \\
\hline BELE-SAMA & 157.23 & -7.2 & -0.046 & 207.76 \\
\hline DAJK-KHOJ & 163.34 & -15.9 & -0.097 & 205.79 \\
\hline DAJK-FARA & 157.76 & -20.2 & -0.128 & 210.02 \\
\hline DAJK-SAMA & 148.64 & -5.3 & -0.036 & 200.40 \\
\hline KHOJ-FARA & 13.615 & 8.2 & 0.602 & 123.69 \\
\hline KHOJ-SAMA & 21.272 & -5.4 & -0.254 & 20.00 \\
\hline FARA-SAMA & 28.436 & 4.1 & 0.144 & 350.72 \\
\hline
\end{tabular}

\section{Acknowledgements}

Fieldwork carried out by CMMACS in February and July 2001 was funded by a special grant from the Director General, CSIR, Government of India.

\section{References}

Anatoli 2001 Rupture parameters of the 26 Jan 2001 earthquake derived from teleseismic data; EOS Transactions of the American Geophysical Union, June 2001
Bendick R, Bilham R, Fielding E, Gaur V K, Hough S, Kier G, Kulkarni M N, Martin S, Mueller K and Mukul M 2001 The January 26, 2001 "Republic Day" Earthquake, India; Seism. Res. Lett. 72(3), 328-335

Blume F 1999 Determination of source parameters of the great 1934 Nepal earthquake using historic and modern geodesy; Ph. D. Thesis, University of Colorado

Bodin P and 7 other authors, 2001 Aftershocks of the Gujarat, India, Republic Day earthquake; Abs. Seism. Res. Lett. 72397

Burrard S G 1889 in Great Trigonometrical Survey of India, Volume 14 (ed) W H Cole S. W. Quadrilateral, prepared under the orders of H. R. Thuillier, Dehra Dun 1890 
Chung W-Y and Gao H 1995 Source mechanism of the Anjar, India, earthquake of 21 July, 1956 and its seismotectonic implications for the Kutch rift basin; Tectonophysics 242 281-292

Cole W H 1890 Great Trigonometrical Survey of India, Volume 14, South West Quadrilateral, Prepared under the orders of H. R. Thuillier, Dehra Dun 1890

De Graaff Hunter J 1918 The earth's axis and triangulation, professional paper 16, Survey of India, Dehra Dun., pp. 219

Gowd T N, Srirama Rao S V and Chary K B 1996 Stress field and seismicity in the Indian Shield: Effects of the collision between Indian and Eurasia; Pageoph. 146 1-27

Gulatee B L 1935 Geodetic Report of Survey of India 1934, Chapter VII, Research and Technical Notes, Dehra Dun 1935

Gulatee B L 1950 Geodetic Triangulation in Kutch; Survey of India Technical Report 1948-49, Dehra Dun 1950

Gwyn A H 1928 Leveling 1922-23, in Geodetic Report Survey of India (ed) E A Tandy 1 194-286

Jade S, Mukul M, Parvez I A, Ananda M B, Kumar P D and Gaur V K 2002 Estimates of coseismic displacement and post-seismic deformation using global positioning system geodesy for the Bhuj earthquake of January 2001; Curr. Sci. 82 6, March 2002
Nagar V K and Singh A N 1992 An estimate of the vertical velocity field in India from historic leveling data, Internal report; Survey of India, Dehra Dun

Negishi H, Mori J, Sato T, Singh R, Kumar S, Hirata N 2002 Size and orientation of the fault plane for the 2001 Gujarat, India Earthquake (Mw7.7) from aftershock observations: A high stress drop event; Geophys. Res. Lett. 291949

Sato T and 17 other authors, A comprehensive survey of the 26th January 2001 earthquake $\left(M_{w} 7.7\right)$ in the state of Gujarat, India, December 2001, 117p

Strahan G 1893 Descriptions and coordinates of the principal and secondary stations and other fixed points of the Cutch Coast Series, or Series L, of the South West Quadrilateral; Synopsis of the results of the Great Trigonometrical Survey of India 33 Dehra Dun

Survey of India 1950 Technical Report, 1948-9, Dehra Dun

Toda S, Stein R S, Reasenberg P A and Dieterich J H 1998 Stress transferred by the $M_{w}=6.5$ Kobe, Japan, Shock: Effect on aftershocks and future earthquake probabilities; J. Geophys. Res. 103 24543-24565

Thuillier H R 1894 Kathiawar Meridional Series; Synoptical Volume of the Great Trigonometrical Survey of India $\mathbf{3 4}$ Dehra Dun 